\title{
Toxicidad sistémica por anestésicos locales en paciente con hipoalbuminemia severa. Reporte de un caso
}

\author{
Case report Local anesthetic toxicity due \\ to hypoalbuminemia
}

Agustina Castro Lalín', Guillermo Tajtelbaum G. ${ }^{1}$

\begin{abstract}
Local anesthetics are drugs widely used to perform peripheral nerve blocks. Signs and symptoms of toxicity may vary from mild to severe, including neuro and cardiotoxicity, with seizures and cardiac arrest. We present the case of an 85-year-old patient in total left knee replacement plan due to tibial saucer fracture, where systemic toxicity was observed by local anesthetics (LAST) after performing a femoral nerve block guided by neurostimulation and ultrasound with a solution of $20 \mathrm{ml}$ of $0.525 \%$ ropivacaine $+0.6 \%$ lidocaine. As a positive data, the patient presented severe hypoalbuminemia
\end{abstract}

\section{RESUMEN}

Los anestésicos locales son fármacos ampliamente utilizados para realizar bloqueos nerviosos periféricos. Los signos y síntomas de toxicidad pueden variar de leves a severos, incluidas la neuro y cardiotoxicidad, con convulsiones y paro cardíaco. Presentamos el caso de una paciente de 85 años de edad en plan de reemplazo total de rodilla izquierda debido a fractura de platillo tibial, donde se observó toxicidad sistémica por anestésicos locales (LAST por su sigla en inglés) después de realizar un bloqueo del nervio femoral guiado por neuroestimulación y ultrasonido con una solución de $20 \mathrm{ml}$ de ropivacaína al 0,525\% + lidocaína al 0,6\%. Su único antecedente médico era presentar hipoalbuminemia severa.

\section{Key words:}

Local anesthetics, toxicity,

hypoalbuminemia

\section{Palabras clave:}

Anestésicos locales, intoxicación, hipoalbuminemia

Departamento de Anestesiología, Hospital Italiano de Buenos Aires. Argentina.

Fecha de recepción: 29 de noviembre de 2019

Fecha de aceptación: 02 de diciembre de 2019

\section{ORCID}

https://orcid.org/

Correspondencia:

Dra. Agustina Castro Lalin

Email: castrolalinagustina@gmail.com 


\section{Introducción}

L os anestésicos locales (AL) son agentes ampliamente utilizados para realizar bloqueos nerviosos - periféricos. Tienen una alta tasa de unión a las proteínas plasmáticas, principalmente a la albúmina y a la alfa 1 glicoproteína ácida, ambas sintetizadas en el hígado. La albúmina no es un transportador específico, pero la alfa 1 glicoproteína ácida sí lo es. Sin embargo, el transporte de AL unido a la albúmina es más importante dada su abundancia en plasma, mientras que la alfa 1 glicoproteína ácida se encuentra en concentraciones más bajas y se satura más rápido. Por lo tanto, los niveles de albuminemia son de vital importancia para el transporte de AL. El desarrollo y la intensidad de la toxicidad dependen de los factores de riesgo propios del paciente (afección cardiovascular, función hepática y niveles de pH extremos), medicación concomitante, localización y técnica de bloqueo, velocidad y presión de inyección y dosis utilizadas. Existe literatura que asocia el sexo femenino con picos plasmáticos más altos de ropivacaína[1]. Los signos y síntomas de LAST pueden variar desde leves (sabor metálico, parestesia perioral, tinnitus, vértigo) hasta moderados (taquicardia, confusión, agitación, disartria, disforia) y severos (cardio y neurotoxicidad, con convulsiones, bradicardia marcada, hipotensión e incluso paro cardíaco).

Una forma de prevenir el LAST es administrando la dosis efectiva más baja, aspirando con la jeringa antes de cada inyección e inyectando 3 a $5 \mathrm{ml}$, cada 15 segundos, mientras se observa por ultrasonido tanto la aguja como la dispersión de AL[2].

El uso de ultrasonido se asocia con una incidencia reducida de toxicidad por anestésicos locales. El sitio de la inyección, el tipo de anestésico local, la dosis y el peso del paciente son factores predictivos de LAST[3].

La hipoalbuminemia tiene múltiples causas, como disminución de la síntesis, aumento de las pérdidas renales, aumento del catabolismo, aumento del volumen plasmático y mala distribución de la albúmina total en el cuerpo. Es frecuente en pacientes con un estado nutricional deficiente[4], inmovilización prolongada y enfermedades críticas[5], por lo que es muy común entre los pacientes hospitalizados. Se ha informado que el $20 \%$ de los pacientes que ingresan a la sala de emergencias en los EE.UU., el $67 \%$ en Brasil y el $81,5 \%$ en Perú tienen hipoalbuminemia. Esto se ha relacionado con el aumento de la mortalidad, la morbilidad, la extensión de su estancia hospitalaria y la necesidad de cuidados intensivos. También se ha encontrado que los niveles séricos bajos de albúmina se asocian generalmente con hipocalcemia, uremia y alteraciones en la potasemia, que, por sí mismas, pueden causar arritmias ventriculares y muerte[6].

La albúmina sérica predice la mortalidad a los 30 días en pacientes en emergencias médicas[7].

La toxicidad sistémica por anestésicos locales se puede revertir mediante el uso de terapia de emulsión de lípidos intravenosa al 20\% (LES), que se utiliza principalmente para la prevención del colapso cardiovascular. Se administra una dosis inicial de $1,5 \mathrm{ml} / \mathrm{kg}$ con un bolo posterior de $0,25 \mathrm{ml} / \mathrm{kg} / \mathrm{min}$, el cual puede repetirse si reaparece la inestabilidad[8]. Se han reportado recurrencias hasta cuarenta minutos después del final de la terapia, por lo que se recomienda el monitoreo durante al menos 12 horas.

\section{Descripción del caso}

Presentamos el caso de una paciente femenina ASA II, de 85 años de edad, en plan de reemplazo total de rodilla izquierda debido a una fractura de platillo tibial. Su peso era de $65 \mathrm{~kg}$ y su altura de 1,6 $\mathrm{m}$. Como antecedente patológico presentaba hipertensión y no refería alergias conocidas. Había sido internada once días antes, momento desde el cual se encontraba postrada y cumplía ayuno al momento de la intervención. Las pruebas de laboratorio mostraron un nivel de hematocrito del $25 \%$, creatinina en sangre de $0,23 \mathrm{mg} / \mathrm{dl}$ y albuminemia de $1,6 \mathrm{~g} / \mathrm{dl}$ (valor estándar de 3,4 a 5,4 g/dl) como datos positivos. Como parte de su plan anestésico, se realizó un bloqueo del nervio femoral guiado por ultrasonido y neuroestimulación en la sala de pre-anestesia. Como sedación se administraron $2 \mathrm{mg}$ de midazolam y para el bloqueo periférico una solución de $20 \mathrm{ml}$ de ropivacaína al 0,525\% + lidocaína al 0,6\% con una aguja Stimuplex ${ }^{\circledast}$ de $100 \mathrm{~mm}$. La inyección intravascular se evitó satisfactoriamente aspirando con la jeringa antes de la administración mientras se observaba a través de ultrasonido tanto la aguja como la dispersión de AL. Los signos vitales (frecuencia cardíaca, saturación de oxígeno y presión arterial) se midieron durante todo el procedimiento y se mantuvieron estables.

Inmediatamente después del bloqueo, la paciente fue trasladada al quirófano para realizarse la cirugía. Al conectarla al monitor de vitales, éste evidenció una rápida desaturación de $\mathrm{O}_{2}$ del $70 \%$ y una frecuencia cardíaca de 30 latidos por minuto. La presión arterial estaba dentro del rango normal y el ECG mostraba un ritmo sinusal. La paciente estaba desorientada y no respondía a órdenes simples o incluso a su nombre. Presentó signos de dificultad respiratoria, como retracciones y uso de músculos respiratorios acceso- 
rios. Se colocó una máscara facial con $\mathrm{FiO}_{2}$ al $100 \%$ a $8 \mathrm{l} / \mathrm{min}$ para mejorar la oxigenación y se llevaron a cabo maniobras de desobstrucción de las vías respiratorias (subluxación mandibular). Se necesitó apoyo hemodinámico y se administraron $1 \mathrm{mg}$ de atropina (con buena respuesta) y 0,3 mg de flumazenil por vía intravenosa, ya que se sospechaba que su condición era el resultado de una respuesta insatisfactoria a las benzodiazepinas. Dado que las únicas otras drogas utilizadas fueron la ropivacaína y la lidocaína, el LAST se identificó rápidamente. Por lo tanto, se administraron dos bolos de 1,5 ml/kg de emulsión lipídica endovenosa al 20\% para revertirlo y prevenir el colapso cardiovascular. Como no hubo mejoría en las funciones respiratorias o sensoriales, la vía aérea se aseguró a través de intubación orotraqueal, previa relajación neuromuscular con $30 \mathrm{mg}$ de rocuronio IV. Se insertó una línea arterial y la sangre extraída mostró un nivel de $\mathrm{PCO}_{2}$ de $71 \mathrm{mmHg}$, una lactacidemia de $5,69 \mathrm{mmol} / \mathrm{L}$ y un $\mathrm{pH}$ de 7,22 . La hipercapnia y la acidosis favorecieron la perpetuación de los síntomas neurológicos. La terapia con solución lipídica al 20\% no revirtió el estado neurológico del paciente. La misma fue trasladada a la $\mathrm{UCl}$ en asistencia respiratoria manual y bajo monitoreo de signos vitales. Una vez allí, se realizó una tomografía computarizada para descartar la posibilidad de un accidente cerebrovascular como diagnóstico diferencial de LAST, la cual no arrojó resultados positivos. Una resonancia magnética del cerebro posterior reveló una lesión cerebelosa subaguda, que no justificaría su condición clínica.

Una prueba de orina completa no evidenció proteinuria ni microalbuminuria.

La paciente permaneció en asistencia respiratoria mecánica durante tres días bajo sedoanalgesia intra- venosa con dexmedetomidina, en proceso de weaning, y finalmente se extubó satisfactoriamente con restitución del sensorio ad integrum y sin ningún tipo de secuela.

Fue dada de alta y se acordó con el equipo médico realizar un tratamiento no quirúrgico de su patología.

\section{Discusión}

Teniendo en cuenta que se tomaron todas las precauciones necesarias para evitar la inyección intravascular de AL y que la técnica y la dosis fueron correctas, interpretamos LAST como secundario a la hipoproteinemia presentada por la paciente y asumimos que los bajos niveles de albúmina y otras proteínas sintetizadas en el hígado habrían provocado un aumento en la fracción libre de AL y, por lo tanto, de sus efectos nocivos.

Creemos que la relevancia de este caso radica en el hecho de que la neurotoxicidad observada no fue la típica que LAST puede producir, ya que no hubo convulsiones sino un deterioro sensorial grave, y que la intoxicación se debió a la hipoproteinemia del paciente y no a un error en la dosis o una inyección intravascular de AL, que se encuentran entre sus causas más comunes.

Destacamos la detección temprana y el tratamiento de LAST con terapia de emulsión lipídica al 20\%, ya que consideramos que hubo poca inestabilidad hemodinámica gracias a la aplicación veloz de la misma.

Lo que hemos aprendido de este caso es la importancia de revisar el proteinograma del paciente para detectar la hipoalbuminemia previo a realizar un bloqueo nervioso periférico.

\section{Referencias}

1. Miller RJ, Cameron AJ, Dimech J, Orec RJ, Lightfoot NJ. Plasma Ropivacaine Concentrations Following Local Infiltration Analgesia in Total Knee Arthroplasty: A Pharmacokinetic Study to Determine Safety Following Fixed-Dose Administration. Reg Anesth Pain Med. 2018 May;43(4):34751. https://doi.org/10.1097/ AAP.0000000000000727 PMID:29369957
2. Neal JM, Mulroy MF, Weinberg GL; American Society of Regional Anesthesia and Pain Medicine. American Society of Regional Anesthesia and Pain Medicine checklist for managing local anesthetic systemic toxicity: 2012 version. Reg Anesth Pain Med. 2012 Jan-Feb;37(1):16-8. https://doi.org/10.1097/ AAP.0b013e31822e0d8a PMID:22189574

3. Barrington MJ, Kluger R. Ultrasound guidance reduces the risk of local anesthetic systemic toxicity following peripheral nerve blockade. Reg Anesth Pain Med. 2013 Jul-Aug;38(4):289-99. https://doi.org/10.1097/ AAP.0b013e318292669b PMID:23788067

4. Kuzuya M, Izawa S, Enoki H, Okada K, Iguchi A. Is serum albumin a good marker for malnutrition in the physically impaired elderly? Clin Nutr. 2007 Feb;26(1):84-90. https://doi. org/10.1016/j.clnu.2006.07.009 
PMID:16996659

5. Nicholson JP, Wolmarans MR, Park GR. The role of albumin in critical illness. Br J Anaesth. 2000 Oct;85(4):599-610. https://doi.org/10.1093/ bja/85.4.599 PMID:11064620

6. Cieza JA, Casillas A, Da Fieno AM, et al. Association between serum albumin and abnormalities in serum electrolytes, blood gases and nitrogen compounds in adult patients attending an emergency room of a general hospital. Rev Méd Hered. 2016;27:223-9. https://doi. org/10.20453/rmh.v27i4.2991.

7. Lyons $O$, Whelan B, Bennett K, O'Riordan D, silke B. Serum albumin as an outcome predictor in hospital emergency medical admissions. Eur J Intern Med. 2010 Feb;21(1):17-20. https://doi. org/10.1016/j.ejim.2009.10.010 PMID:20122607
8. Neal JM, Bernards CM, Butterworth JF 4th, Di Gregorio G, Drasner K, Hejtmanek MR, et al. ASRA practice advisory on local anesthetic systemic toxicity. Reg Anesth Pain Med. 2010 Mar-Apr;35(2):152-61. https://doi.org/10.1097/ AAP.0b013e3181d22fcd PMID:20216033 